\title{
Relatos de médicos sobre a experiência do processo de morrer e a morte de seus pacientes
}

\author{
Medical reports about the experience of the dying process \\ and the death of his/her patients
}

\author{
Jacqueline Kaori Tozaki Tamada ${ }^{1}$, Aline Skawinski Dalaneze ${ }^{1}$, \\ Luci Mendes de Melo Bonini ${ }^{2}$, Tatiana Ribeiro de Campos Melo ${ }^{3}$
}

Tamada JKT, Dalaneze AS, Bonini LMM, Melo TRC. Relatos de médicos sobre a experiência do processo de morrer e a morte de seus pacientes / Medical reports about the experience of the dying process and the death of his/her patients. Rev Med (São Paulo). 2017 abr.-jun.;96(2):81-7.

RESUMO: A morte é concebida diferentemente em cada cultura, e, sendo assim, cada povo tem uma forma de abordar, estudar e debater seus conceitos. Entre os médicos não é diferente, pois ela faz parte de sua profissão, principalmente nas especialidades que lidam com as situações terminais. $\mathrm{O}$ objetivo dessa pesquisa foi compreender como os médicos, de diferentes especialidades, encaram a morte iminente ou constatada de pacientes e identificar se houve, na sua formação acadêmica, algum preparo para isso. Esta pesquisa foi descritiva, de abordagem qualitativa e de corte transversal. Através de uma entrevista semiestruturada, cada um dos 9 profissionais abordados expressou o seu entendimento sobre a morte e relatou seu preparo para lidar com ela. Para análise dos dados quantificou-se gênero, idade e tempo de formação. Para as respostas abertas, criaram-se três categorias: 1) como cada profissional encara a morte do seu paciente; 2) se houve algum preparo para lidar com a morte de seus pacientes (formal ou não); 3) renovação de energias.

Descritores: Educação médica; Morte; Médicos; Saúde pública.

\begin{abstract}
Death is conceived differently in every culture, every people has a way to address, study and discuss their concepts. Among physicians, it is no different, for it is part of their profession, specifically the specialties that deal with the terminal patients. The objective of this research was to understand how physicians from different specialties, face imminent or established patient's death and identify whether there was, in his academic background, some preparation for it. This research is descriptive qualitative approach, cross-sectional. Through a semi-structured interview, 9 professionals from different specialties expressed, in different ways, how they understand death and how they prepare to deal with it. For the later analysis, it was quantified: gender, age and training time. And as for the opened answers, 3 categories were created: 1) How each professional deal with the death of their patient; 2) if there was any kind preparation to deal with their patient's death (formal or not); 3) Energy's renovation.
\end{abstract}

Keywords: Education, medical; Death; Physicians; Public health.

Trabalho apresentado no XVIII Congresso de Iniciação Científica da Universidade de Mogi das Cruzes, 2015.

1. Estudante de Medicina da Universidade de Mogi das Cruzes. Email: jacquelinetozaki@yahoo.com.br, alinedalaneze@gmail.com.

2. Dra. em Comunicação e Semiótica pela PUC-SP, pesquisadora no Mestrado em Políticas Públicas da Universidade de Mogi das Cruzes (UMC) e do Instituto de Pesquisas Tecnológicas (IPT-USP). Email: lucibonini@gmail.com.

3. Coordenadora do Curso de Odontologia e pesquisadora no Mestrado em Políticas Públicas da Universidade de Mogi das Cruzes (UMC). Email: tatianar@umc.br.

Endereço para correspondência: Jacqueline Kaori Tozaki Tamada. Av. Coral, 614 - bairro Perová. Arujá, SP. CEP: 07428-075. Email: jacquelinetozaki@yahoo.com.br. 


\section{INTRODUÇÃO}

A morte suscita várias abordagens e pode ser definida como a perda de fluidos vitais, a separação da alma, a perda irreversível da capacidade de integração do corpo ou da capacidade de consciência e integração social. A maneira como cada comunidade/grupo social ou mesmo um sujeito a compreende depende sempre de fatores religiosos, sociais e culturais.

$\mathrm{O}$ avanço da ciência e da tecnologia na área da saúde trouxe para o médico uma responsabilidade ainda maior na sua missão de curar, pois os diagnósticos estão cada vez mais precisos e os medicamentos têm seu espectro ampliado cada vez mais. Isto, por sua vez, pode trazer uma maior sensação de fracasso quando o paciente morre ${ }^{1}$. Os atuais critérios aceitos para morte são o cessar irreversível do funcionamento de todas as células, tecidos e órgãos; do coração e dos pulmões; de todo o encéfalo; do córtex cerebral; do tronco cerebral; da capacidade corporal da consciência².

Além desta definição, voltada para visão da morte biológica do corpo, surge uma outra, que é a construção cultural da morte. Sob este ponto de vista, a morte ainda é considerada um tabu em pleno século XXI pois está associada sentimentos de dor, sofrimento, separação e perda ${ }^{3}$. Desta forma, a morte passa a ter um efeito ainda mais desastroso no cenário atual, em que se está culturalmente fundamentado valores como a supervalorização da beleza e do aspecto saudável. Há ainda, o conceito de aproveitar a vida que foi eternizado pelo filósofo Horácio em sua frase em latim Carpe Diem 4 . Por todos esses conceitos e valores incorporados na sociedade, torna-se problemático abordar o assunto morte, visto que ele está ligado à incapacidade das pessoas de não conseguirem abordar este assunto no seu dia-a-dia.

Durante a formação acadêmica, em um projeto de iniciação científica, foi realizado um estudo no qual se perguntava: como os médicos lidam com a morte? Há algum tipo de formação específica para este enfrentamento? A pesquisa buscava entender se era necessária uma maior introdução sobre a morte nas escolas de medicina desde o início do curso ou se os médicos, naturalmente, buscavam alguma forma de lidar com a morte, além daquela estabelecida na Resolução 1.805/2006 ${ }^{5}$. Os resultados mostraram que os profissionais buscam novas soluções a fim de se tornarem mais aptos a lidar com a morte ${ }^{6}$.

\section{Os médicos diante da morte e do morrer}

Com o avanço da Medicina, ora cada vez mais biotecnológica, os médicos tendem a focar mais no diagnóstico, tratamento e prevenção de uma determinada doença, do que na cura propriamente dita. Logo, a cura prevalece sobre o cuidado e o médico acaba por assumir um papel de "curador da doença" ao invés de "cuidador do doente" . Assumindo tal função, o médico acaba não sabendo lidar com a morte e com o sofrimento humano durante a sua vida profissional, muitas vezes por não ter sido preparado previamente para o enfrentamento destes tabus ao longo de sua formação.

Assim, quando há o envolvimento pessoal do médico, afloram sentimentos de impotência, culpa, fracasso e medo aliados à dificuldade e o despreparo para lidar com a situação ${ }^{8}$. Consequentemente, as dificuldades e os sentimentos de sucesso/insucesso geram uma postura de onipotência/impotência diante do enfrentamento das problemáticas diárias ${ }^{9}$. Todos estes fatores juntos acabam por interferir na relação médico-paciente, a qual deve ser preservada para que não haja prejuízos a ambos.

Em relação à formação, principalmente acadêmica, os estudantes de medicina são preparados para lidar com a morte de um paciente apenas tecnicamente, deixando o lado humano esquecido em muitas vezes. A estes profissionais da saúde cabe a preservação da vida, por isso, acredita-se que seja necessária uma revisão nos currículos dos cursos de medicina que os auxilie na construção de valores, comportamentos, atitudes resilientes e outras formas de enfrentar a morte do paciente sem haver desgastes pessoais.

Por outro lado, diante do morrer e da morte do paciente, este profissional precisa compreender que há de se cultivar formas mais humanas de oferecer dignidade para a família e para aqueles que não têm mais chances de cura. É sob este ponto de vista que Sócrates afirmava na seguinte frase: "o importante não é evitar a morte, o importante é evitar que ela seja injusta".

Relacionando questões bioéticas à prática humanizada da medicina, pode-se inferir com os estudos já realizados que uma das maneiras do profissional estar mais apto a enfrentar a morte é através de uma reflexão sobre a sua própria finitude, tornando-se consciente da inevitabilidade da morte e do morrer ${ }^{10}$. Neste sentido, fazse, aqui, a menção da Resolução 1.805/2006 do Conselho Federal de Medicina (CFM) ${ }^{5}$, a qual vem auxiliando os profissionais a lidarem de maneira profissional com a chegada da morte. Esta resolução trata da suspensão de tratamentos pelo médico em pacientes terminais, desde que seja esta a vontade do doente ou, na sua impossibilidade, de seus familiares ou representantes legais. Esta mudança de encaminhamento da morte dá ao profissional mais habilidade para olhar o outro com mais humanidade e fundamento jurídico para suas práticas cotidianas.

Neste sentido, também, o profissional também deve estar preparado para lidar com a família do paciente. Para haver um bom desenvolvimento do tratamento, é preciso assegurar uma boa interação entre os profissionais da saúde e os familiares do paciente ${ }^{11}$. Assim, casos que envolvem doenças terminais e morte exigem esforços psicológicos maiores tanto dos médicos quanto da família para que haja um melhor entendimento entre as partes durante o tratamento do paciente. Há ainda os médicos que lidam 
diretamente com o morto: os legistas. Para eles, não há a necessidade de tratar o paciente e sua família, embora também necessitem de um equilíbrio psicológico ao lidar com o cadáver.

É sob todas essas diferentes visões e particularidades de cada profissional que esta pesquisa buscou compreender como o médico, de diferentes especialidades, encaram a morte iminente ou constatada de pacientes e identificar se houve, na sua formação acadêmica, algum preparo para isso e, também, buscou-se conhecer como e onde é feita esta reestruturação emocional do profissional.

\section{MÉTODO}

Trata-se de um estudo descritivo, de abordagem qualitativa, de corte transversal. Participaram da pesquisa 9 médicos atuantes na região do Alto Tietê, no período de outubro a dezembro de 2014. Buscaram-se profissionais de diferentes especialidades médicas, desde que estivessem ligadas a perda de pacientes ou a morte: para tanto foi altamente desejável que os participantes da pesquisa fossem: cirurgiões, socorristas, cardiologistas, intensivistas, entre outros. A amostra foi de conveniência, pois foram escolhidos 3 médicos que tinham relação profissional com a faculdade de medicina da região. Posteriormente, cada um dos entrevistados indicou mais dois profissionais.

A coleta de dados foi realizada por meio de uma entrevista semiestruturada (Anexo 1). O questionário elaborado pelas autoras continha 11 perguntas, sendo elas: sexo; idade; tempo de formação; local de formação; qual a especialidade e onde a cursou; qual a frequência de contato com óbitos de pacientes/pacientes terminais; quais as atitudes para com o paciente, com a família do paciente e consigo mesmo diante de uma morte iminente; o que faz para renovar as energias (hobbies, apoio na religião, prática de esportes, etc.); se houve preparo para lidar com o óbito de pessoas; se há realização profissional; quais as atitudes mais importantes em relação à família do morto e consigo mesmo diante de uma avaliação de causa mortis.

O convite para participação na pesquisa, o Termo de Consentimento Livre e Esclarecido e o roteiro da entrevista foram encaminhados para o endereço eletrônico de cada participante. Após a aceitação pelo participante, as entrevistas ocorreram presencialmente. $\mathrm{O}$ trabalho foi aprovado pelo CEP Comitê de Ética e Pesquisa da Universidade de Mogi das Cruzes (CEP), de parecer de $\mathrm{n}^{\circ} 702.747$.

Para análise dos dados quantificou-se gênero, idade e tempo de formação. Para as respostas abertas, criaramse três categorias, sob a orientação da análise de conteúdo de $\operatorname{Bardin}^{12}$ : 1) como cada profissional encara a morte do seu paciente; 2) se houve algum preparo para lidar com a morte de seus pacientes (formal ou não); 3 ) renovação de energias. Além destas três grandes categorias, as primeiras duas categorias ainda apresentaram subitens como forma de se ilustrar melhor o resultado das entrevistas.

\section{RESULTADOS E DISCUSSÕES}

Não houve pré-requisitos como idade, tempo de formação, especialidade e local de formação durante o processo de escolha dos profissionais, sendo assim, participaram da pesquisa 7 médicos e 2 médicas de faixas etárias distintas, tendo o participante mais jovem 32 anos de idade e o mais velho 58 anos.

O tempo de formação e o local de formação também variaram bastante, desde 7 até 34 anos de formação em escolas médicas distintas (particulares e públicas) e todas tinham em comum o fato de serem escolas paulistas. Além disso, todos os médicos eram atuantes na região do Alto Tietê em diferentes órgãos de saúde, tanto públicos como privados.

As especialidades foram das mais distintas, variando desde especialidades de caráter cirúrgico até aquelas de caráter puramente clínico. Assim, participaram: 3 médicos legais e peritos médicos, 1 cirurgião geral, 1 cirurgião geral com especialidade em pós-terapia intensiva, 1 cardiologista, 1 pneumologista, 1 cirurgião de cabeça e pescoço e 1 cirurgião geral com especialidade em aparelho digestivo.

\section{Como cada profissional encara a morte}

Existem diferentes formas de encarar a morte para cada um dos participantes, independentemente do tempo de formação, da especialidade ou da frequência de contato com óbitos e pacientes terminais. Dentre os médicos que colaboraram na pesquisa, observou-se um amplo leque de conceitos e reações.

\section{a) Com envolvimento pessoal}

Não gosto de morte. Faço o possível para manter o paciente vivo, não gosto da sensação de impotência (Cirurgia Geral e Clinica Médica, Feminino, 53 anos, 25 anos de formada).

Me envolvo, faço terapia, e fico mal. Eu choro, mas nunca pensei em desistir, pois se eu não tratar quem vai tratar. So u muito amoroso e gosto de ficar perto dos meus pacientes (Cirurgia Cabeça e Pescoço, Masculino, 43 anos, 20 anos de formado).

Cada profissional tem uma atitude diante da morte, alguns se envolvem outros conseguem se distanciar. Observa-se que buscam uma atitude humanista diante do paciente, e entendem que necessitam buscar algum tipo de ajuda e conforto para si mesmos, pois sabem que novos pacientes virão em busca de ajuda e o óbito é inerente à profissão que escolheram.

Na rotina profissional o médico sabe que não deve ficar afetado em demasiado pela perda do paciente, já que muitos outros necessitam de sua força combativa ${ }^{13}$, ter domínio das emoções negativas para com o próximo e reconhecer suas dificuldades e procurar soluções para 
Tamada JKT, et al. Relatos de médicos sobre a experiência do processo de morrer e a morte de seus pacientes.

enfrentar seus conflitos pessoais ${ }^{14}$.

O cotidiano de profissionais revela que quanto mais intenso o vínculo com o paciente maior o sentimento de impotência e a inevitabilidade da morte desperta sentimentos de fracasso como se a morte tivesse sobrepujado a dedicação de toda a equipe ${ }^{15}$.

Identificou-se, em estudos anteriores ${ }^{16}$, que para aos profissionais da saúde transmitirem notícias ruins é difícil. Logo há uma busca para fugir de envolvimentos e emoções fortes para evitar o sofrimento com as perdas e assim a adoção de atitudes defensivas, ou ainda para controlar os sentimentos de ansiedade, impotência e revolta ${ }^{16}$.

Também foi observado em pesquisas pregressas que oncologistas têm demonstrado dificuldades quando perdem pacientes, principalmente os casos em que eles ficaram mais próximos dos pacientes e suas famílias, ou ainda quando os pacientes eram jovens, ou ainda quando a morte foi inesperada ${ }^{17}$.

Parkes $^{18}$, estudioso do processo de luto na sociedade e de suas implicações, sugere em suas pesquisas que o médico pode e deve pedir ajuda de alguém de sua confiança em algum momento de seu luto. Com isso, o profissional deve estar preparado para deixar outras pessoas o auxiliarem temporariamente para poder vivenciar a sua perda, tornando este processo um período de intenso amadurecimento emocional.

\section{b) Sem envolvimento pessoal}

Atualmente consigo lidar de maneira diferente em relação a época que era recém formada. Me mantenho atenta para não perder o foco. Tento ser profissional, e tratar todos da melhor maneira possivel (Pneumologia, Feminino, 55 anos, 32 anos de formada).

A morte é uma coisa natural da vida, assim como nascer. O morrer é um segundo parto, é uma etapa (Proctologia, Masculino, 58 anos, 34 anos de formado).

Uma outra postura está na crença de que o bom profissional privilegia a técnica, evitando, dessa forma, proximidade emocional ${ }^{19}$. Talvez essa crença tenha levado à conclusão de que alertar o paciente sobre a sua morte iminente aumenta a qualidade de vida, dando escolhas de como passar seus últimos dias, quais tratamentos optar, o que deseja realizar e assim lhes dando maior dignidade ${ }^{20}$. Além disso, há uma possibilidade dada ao paciente de viver este período que precede a morte como mais um momento de crescimento e transcendência, uma oportunidade para resolver pendências pessoais e relacionais e um tempo suficiente para encontrar seus recursos internos de resiliência ${ }^{20,19}$.

\section{Preparo (formal e não-formal) para lidar com a morte}

\section{a) Sem preparo}

A formação acadêmica não prevê nas grades curriculares ou práticas interdisciplinares que discutam a morte com seus diferentes enfoques em diferentes culturas. Logo, é mais uma vez a vivência cotidiana que foi apontada como base da aprendizagem sobre a atitude profissional diante da morte ${ }^{11}$. Cinco participantes afirmaram não existir nenhum tipo de preparo para lidar com a morte do paciente e, quando questionados como se prepararam, as respostas foram diferentes:

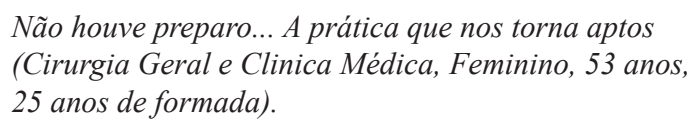

Não existe preparo e nenhum protocolo para lidar com o óbito. Sempre tento me manter calmo, explicar e demonstrar a causa da morte, assim como tento me colocar à disposição para diminuir o sentimento da perda (Cardiologia, Masculino, 32 anos, 7 anos de formado).

Nunca me preparei... Aprendo mais com a rotina diária (Cirurgia geral e aparelho digestivo, Masculino, 34 anos, 7 anos de formado).

Não houve nada específico na formação. O dia a dia é que nos prepara (Cirurgia geral e aparelho digestivo, Masculino, 32 anos, 8 anos de formado)

A formação para encarar a morte, principalmente das especialidades que vivem mais próximas a ela, deve ser prevista no cenário atual, uma vez que o conceito de morte vem sendo redefinido ao longo das últimas décadas, principalmente com o estabelecimento de critérios sobre a morte encefálica ${ }^{21}$.

Estudos ainda apontam que os residentes estão na melhor fase para receber esse preparo, pois aprendem várias habilidades clínicas básicas, e, por isso, estão mais abertos a novas experiências e oportunidades, principalmente para se desenvolver atitudes e conhecimentos necessários para o cuidado humanizado com a morte ${ }^{22}$.

\section{b) Com preparo}

Quatro participantes afirmaram que existiu preparo, seja em forma de cursos ou mesmo uma busca por informações:

Procuro me inteirar antes do caso, examino a família para saber como lidar. Já fiz 8 anos de Terapia e leio bastante (Cirurgia de cabeça e pescoço, Masculino, 43 anos e 20 anos de formado).

Leio livros e faço parte do Movimento Focolarista ${ }^{23}$ (Proctologia, Masculino, 58 anos, 34 anos de formado).

Ao longo do tempo, fiz cursos para transmissão de informação para pacientes paliativos. UTI-deve haver um preparo extra, psicológico para os médicos. Para ter um preparo psicológico, principalmente se tratando de pacientes terminais é necessário para se conseguir apoio (Intensivista, Masculino, 36 anos, 10 anos de formado).

A medicina, que avança na tecnologia e na ciência numa velocidade exponencial, vê a morte súbita se 
desvanecer, pois a maioria dos óbitos hospitalares ocorrem nas unidades de terapia intensiva ${ }^{24}$. Nesses locais ocorrem inúmeras oportunidades de reflexão, seja dos profissionais de saúde, seja dos familiares e seja por conta dos laços que se constroem entre estas duas engrenagens cujo eixo é o paciente.

Resultados entre 413 médicos no México apontam que $28 \%$ receberam treinamento sobre a morte e quase a metade dos médicos relatou uma experiência de formação pessoal relacionada com a morte, que, em conjunto com a experiência de estar exposto a pacientes em estado terminal, parece ser a maneira pela qual a maioria dos médicos aprendem a lidar com a morte ${ }^{25}$.

\section{Renovação de energias}

A medicina é uma das profissões que requer dedicação integral por parte do médico, porém é necessário que haja válvulas de escape na tentativa de manter a saúde mental e a qualidade de vida. Todos alegaram que ter uma válvula de escape é imprescindível para aliviar o estresse, são exemplos: apoio na religião/espiritualidade, leituras, estar com a família, praticar esportes e ter hobbies como tocar instrumentos musicais, pilotar avião, dar aula, andar de moto, viajar.

Através da vivência e do estudo da espiritualidade (experiência de quase morte, vidas passadas) (Pneumologia, Feminino, 55 anos, 32 anos de formada).

Já fiz terapia, li livros sobre maneiras diferentes de ver a morte, principalmente livros do Drauzio Varela (Medicina de Tráfego, Masculino, 33 anos, 9 anos de formado).

É necessário que haja um equilíbrio entre as horas de trabalho com o tempo livre para recuperação, aproveitando-se do apoio familiar e dos amigos, ou ainda em conjunto com "tutores emocionalmente experientes, profissionalmente maduros e interessados". Pesquisas mostram que trabalhar com o que se gosta e não por obrigação, além de diversificar seu lado profissional, torna o indivíduo mais interessado em buscar soluções criativas para o tratamento dos pacientes ${ }^{16}$.

Além do déficit no processo acadêmico, a falta de preparo diante da morte advém da falha dos programas de treinamento médico para que o tratamento dos moribundos não sejam desnecessariamente dolorosos ${ }^{17}$. Neste sentido, entende-se que um processo mais eficaz de humanização do homem frente à sua vida e a dos outros deve estar presente, pois fazem parte dos objetivos da medicina: a prevenção da doença e do sofrimento, a promoção e manutenção da saúde, o alívio da dor e do sofrimento, a cura e cuidado das pessoas com doenças curáveis e daquelas cujas doenças não são curáveis, evitar a morte prematura e buscar uma morte em paz ${ }^{1}$.

Nenhum participante citou a Resolução 1805/06 do $\mathrm{CFM}^{5}$, por isso entende-se, até este ponto, que encarar a própria vida com espiritualidade como fundamento da qualidade de vida parece mais importante do que a base jurídica, ou ainda, falta-se esta discussão em congressos e simpósios com o tema específico.

\section{CONSIDERAÇÕES FINAIS}

Pelo posicionamento dos profissionais, entendeuse que a presença de válvulas de escape é imprescindível para liberar um pouco da tensão/preocupação criada pelo trabalho, evitando grande estresse e sobrecargas emocionais. Essas atividades, por mais simples que pareçam, os ajudam a encarar com mais leveza os problemas que ocorrem no dia-a-dia.

Uma proposta para contribuir na formação do médico e dos demais profissionais da saúde seria abordar estas questões em momentos diferentes da formação: em workshops, na sala de aula, nas clínicas, nos internatos, etc. Dessa forma, poderia se compreender que não existe um duelo, mas sim, um processo natural de todo o ser vivo e que o seu papel é cuidar do doente. Tal cuidado pode ser manifestado através de um tratamento digno e humanizado, que esgote os recursos que conduzem à cura, conduzindo a uma atitude responsiva do médico com relação à gestão pública da saúde. Além disso, ao lutar pela melhoria da qualidade de vida dos pacientes e, consequentemente, da sua, melhor será a qualidade dos serviços propostos para a população e melhor será a relação estabelecida com o paciente.

A manutenção da integridade da relação médicopaciente, principalmente nestes casos em que há morte e sofrimento, é fortificada quando o profissional privilegia o doente sobre sua doença, minimizando sua dor como um todo e focando o tratamento na pessoa mais do que na doença ${ }^{26}$. Dessa maneira, a abordagem frente ao enfrentamento do sofrimento humano, seja na forma de doença e ou de morte propriamente dita, se torna mais tolerável e menos sujeito a prejuízos psíquicos a ambas partes: médico e paciente.

Para aqueles que já estão no meio lidando com as dificuldades que o assunto transmite, é indicado que o médico também se dedique a outras áreas da sua vida, como por exemplo: familiar, pessoal, religiosa e pratique hobbies. No geral, o importante é fazer o que lhe faz bem fora do ambiente de trabalho, a fim de se distrair e encontrar forças para lidar com as situações estressantes. Uma outra forma de lidar com o estresse de alto nível seria procurar um auxílio psicológico de um profissional capacitado. $\mathrm{O}$ importante é o médico perceber o quanto essa renovação de tempo o ajudaria com as dificuldades do dia a dia, sem que sua qualidade de vida fique comprometida. 
Tamada JKT, et al. Relatos de médicos sobre a experiência do processo de morrer e a morte de seus pacientes.

\section{Anexo 1. Questionário}

1.- Sexo? Feminino ( ) Masculino ( )

2. Idade?

3. Quanto tempo de formação?

4- Onde se formou?

5. Qual a especialização? Onde a cursou?

a) Cardiologista

b) Neurologista

c) Oncologista

D) Legista*

E) Outra. Qual?

* Se você assinalou esta alternativa, vá para as questões 10 e 11 apenas.

6. Qual a frequência de contato com óbitos de pacientes/pacientes terminais?
a) Nunca
b) Raramente
c) Frequentemente
d) Diariamente

7. Descreva suas atitudes diante de uma morte iminente, ou seja quando um paciente seu está próximo da morte, quais as ações ou palavras com:
a) $\mathrm{O}$ paciente
b) A família do paciente
c) Você mesmo

8. Diante da iminência da morte de um paciente, o que você faz para renovar as suas energias?

- Hobbie

Qual?

a) Busco apoio na religião/espiritualidade

b) Estar com a família c) Pratico esportes

9. Você se preparou ou se prepara para lidar com o óbito dos pacientes?

- Sim ( )

Como? Descreva

- Não ( )

Por quê?

10. Considera-se uma pessoa realizada profissionalmente? - Sim ( ) - Não ( )

Por quê?

11. Diante da responsabilidade da avaliação da causa mortis quais são as atitudes mais importantes que você toma em relação a: a) Família do morto

b) Consigo mesmo

Agradecimentos: As autoras agradecem a Bolsa de Iniciação Científica, concedida pelo CNPq.

\section{REFERÊNCIAS}

1. Moritz RD. O Efeito da informação sobre o comportamento dos profissionais da saúde diante da morte [tese]. Florianópolis: Universidade Federal de Santa Catarina Programa de PósGraduação em Engenharia de Produção; 2002 [citado 18 abr. 2014]. Disponível em: https://repositorio.ufsc.br/bitstream/ handle/123456789/84198/186845.pdf? sequence=1.

2. Lima C. Do conceito ao diagnóstico de morte: controvérsias e dilemas éticos. 2005. Rev Soc Portuguesa Med Interna. 2005 [citado 6 maio 2014]. Disponível em: http://www.spmi.pt/ revista/vol12/vol12_n1_2005_06-10.pdf.

3. Moritz RD. Os profissionais de saúde diante da morte e do morrer. Bioética. 2005;13(2) [citado 14 maio 2014]. Disponível em: http://www.spmi.pt/revista/vol12/vol12_ n1_2005_06-10.pdf.

4. Significados de Carpe Diem [citado 14 maio 2014]. Disponível em: http://www.significados.com.br/carpe-diem/.

5. Brasil. Conselho Federal de Medicina. Resolução CFM n ${ }^{\circ}$ 1.805/2006 [citado 13 jul. 2016]. Disponível em: http://www. portalmedico.org.br/resolucoes/cfm/2006/1805_2006.htm.

6. Vianna A, Piccelli H. O estudante, o médico e o professor de medicina perante a morte e o paciente terminal. Brasília, DF: Hospital Universitário de Brasília, Faculdade de Ciências da Saúde da Universidade de Brasília; 1998 [citado 22 abr. 2014]. Disponível em: http://www.scielo.br/scielo.php?script=sci_ar ttext\&pid=S0104-42301998000100005.

7. Cassell EJ. The Healer's art. Cambridge, Mass: MIT Press; 1976 [cited 2017 Jan 10].
8. Hoffman L. A morte na infância e sua representação para o médico - reflexões sobre a prática pediátrica em diferentes contextos. Cad Saúde Públ. (Rio de Janeiro). 1993;9(3):36474. Disponível em: www.scielosp.org/pdf/csp/v9n3/23.pdf.

9. Saloum NH, Boemer MR. A morte no contexto hospitalar - as equipes de reanimação cardíaca. Rev Latino-am Enfermagem (Ribeirão Preto). 1999;7(5):109-19. Disponível em: www. scielo.br/pdf/rlae/v7n5/13511.

10. Klüber-Ross E. Sobre a morte e o morrer: o que os doentes terminais têm para ensinar a médicos, enfermeiras, religiosos e aos seus próprios parentes. 9a ed. São Paulo: Martins Fontes; 2008 [citado 5 jul. 2016]. Disponível em: http://faa.edu.br/ portal/PDF/livros_eletronicos/medicina/sobre_a_morte_e_o_ morrer.pdf.

11. Nascimento CAD, Silva AB, Silva MC, Pereira MHM. A significação do óbito hospitalar para enfermeiros e médicos. Rev Rene (Fortaleza). 2006;7(1):52-60. doi: http://dx.doi. org/10.15253/rev\%20rene.v7i1.5369.

12. Bardin L. Análise de conteúdo. Portugal: Edições 70; 1979.

13. Mello AAM, Silva LC. A estranheza do médico frente à morte: lidando com a angustia da condição humana. Rev Abordagem Gestaltica. 2012;18(1):172-84,52-60. Disponível em: http://pepsic.bvsalud.org/scielo.php?script $=$ sci arttext\&pid=S1809-68672012000100008\&lng=pt\&nrm=iso.

14. Dolto F. Psicanálise e pediatria: as grandes noções da psicanalise: 16 observações de crianças. 3a ed. Rio de Janeiro: Guanabara; 1971. 
15. Moraes CJA, Granato TMM. Narrativas de uma equipe de enfermagem diante da iminência da morte. Psicologia. 2014;45(4):475-84. Disponível em: revistaseletronicas.pucrs. br/ojs/index.php/revistapsico/article/.../12474.

16. Almeida MD, Santos APAL. Câncer infantil: o médico diante de notícias difíceis - uma contribuição da psicanálise. Mudanças - Psicol Saúde. 2013;21(1):49-54. Disponível em: https://www.researchgate.net/publication/276225912 Cancer_Infantil_O_Medico_Diante_de_Noticias_Dificeis - Uma_Contribuicao_da_Psicanalise.

17. Pazin-Filho A. Morte - considerações para a prática médica. Simpósio: morte: valores e dimensões. Capítulo 2. Ribeirão Preto; 2005 [citado 6 abr. 2014]. Disponível em: http://revista. fmrp.usp.br/2005/vol38n1/2_morte_consideracoes_pratica_ medica.pdf.

18. Parkes CM. The dying adult. BMJ. 1998;316(7140):1313-5. Disponível em: http://europepmc.org/articles/pmc1113038.

19. Afonso SBC, Minayo MCS. Notícias difíceis e o posicionamento dos oncopediatras: revisão bibliográfica. Ciên Saúde Coletiva. 2013;18(19):2747-56. Disponível em: www.redalyc.org/pdf/630/63028227030.pdf.

20. Houttekier D, Witkamp FE, van Zuylen L, van der Rijt CC, van der Heide A. J Palliative Med. 2014;17(11):1238-43. doi:10.1089/jpm.2014.0203.

Recebido em: 06.10.16

Aceito em: 04.04.17
21. Starzewski JRA, Rolim LC, Morrone LC. O preparo do médico e a comunicação cos familiares sobre a morte. Rev Assoc Med Bras. 2005;51(1):11-6. Disponível em: http:// www.scielo.br/pdf/ramb/v51n1/a13v51n1.pdf.

22. Fins JJ, Nilson EG. An approach to educating residents about palliative care and clinical ethics. Acad Med. 2000;75(6):662-5. Available from: http://journals.lww.com/ academicmedicine/Abstract/2000/06000/An_Approach_to_ Educating_Residents_about.21.aspx.

23. Movimento dos Focolares. Movimento de espiritualidade de âmbito mundial [citado 2016]. Disponível em: http://www. focolares.org.br.

24. Almeida LF, Falcão EBM. Representação social de morte e a formação médica: a importância da UTI. Rev Bras Educ Med. 2013;37(2):226-34. Disponível em: www.scielo.br/pdf/ rbem/v37n2/10.pdf.

25. Álvarez-del-Río AM, Marván ML, Santillán-Doherty P, Delgadillo S, Oñate-Ocaña LF. Facing death in clinical practice: a view from physicians in Mexico. Arch Med Res. 2013;44(5):394-400. doi: 10.1016/j.arcmed.2013.05.005.

26. Cassell, EJ. The nature of suffering: physical, psychological, social, and spiritual aspects. NLN Publ. 1992(15-2461):1-10. [cited 2017 Jan. 10]. 